\title{
NUMERICAL SIMULATION OF THE CRACK 2D BY THE FINITE ELEMENT INCORPORATED THE DISCONTINUITY
}

\author{
Nguyen Truong Giang \\ Institute of Mechanics, VAST
}

\begin{abstract}
Determining stress intensity factors is important in fracture mechanics. The extended finite element method (XFEM) provides a robust and accurate to determine factors. This paper describes some results from the analysis of cracked plates using XFEM. Extended finite elements allow the entire crack to be represented independently of the meshing. The elements employ discontinuous functions and the facture mechanics two dimensional asymptotic crack tip displacement fields. The Fortran source code of Cast3M applies these elements to a set of examples. The obtained stress and deformation fields are used to compute stress intensity factors via interaction integrals. The results are compared with these obtained from conventional FEM to demonstrate the advantages of the employing the new elements.
\end{abstract}

\section{INTRODUCTION XFEM}

\subsection{Governing equation}

Consider a domain $\Omega$, bounded by $\Gamma$. The boundary is partitioned into three sets: $\Gamma_{u}$, $\Gamma_{t}$ and $\Gamma_{c}$ as shown in Fig.1. Displacements are prescribed on $\Gamma_{u}$, tractions are prescribed on $\Gamma_{t}$ and $\Gamma_{c}$ is assumed to be the tractions free.

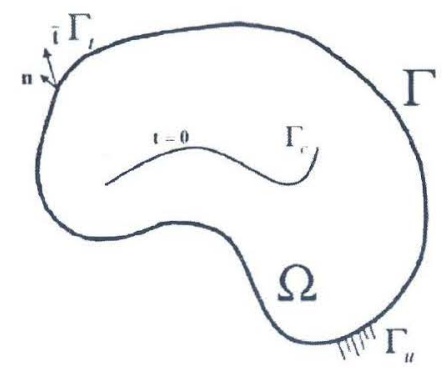

Fig. 1. Body with an internal crack 
The equilibrium equations and boundary conditions for this problem are

$$
\begin{aligned}
& \nabla \cdot \sigma+b=0 \text { in } \Omega \\
& \sigma \cdot n=\bar{t} \text { on } \Gamma_{t} \\
& \sigma \cdot n=0 \text { on } \Gamma_{c} \\
& u=\bar{u} \text { on } \Gamma_{u} .
\end{aligned}
$$

The space of admissible displacement fields is defined by

$$
U=\left\{v \in V: v=\bar{u} \text { on } \Gamma_{u} ; v \text { discontinuous on } \Gamma_{c}\right\} .
$$

The weak form of the equilibrium equations is given by

$$
\int_{\Omega} \sigma(u): \varepsilon(v) d \Omega=\int_{\Omega} b \cdot v d \Omega+\int_{\Gamma_{t}} \bar{t} \cdot v d \Gamma u \in U .
$$

Belytschko and Black, 1999 [3] show that (2) is equivalent to the strong form (1), and includes the traction-free conditions prevailing on the opposing surfaces of the crack.

\subsection{The partition of unity:}

A collection of functions $\varphi_{i}(\mathrm{x})$, each belonging to a node, defined over a body $\Omega(\mathrm{x} \in \Omega$ ) forms a partition of unity (see [1]) if:

$$
\sum_{i=1}^{n} \varphi_{i}(x)=1
$$

where $n$ is the number of nodal points. Using partitions of unity allows us to approximate displacements as:

$$
u^{h}(x)=\sum_{i=1}^{n} \varphi_{i}(x)\left(\sum_{\alpha=1}^{m} \psi_{\alpha}(x) a_{i}^{\alpha}\right),
$$

where $\varphi_{i}$ are partition of unity and $\psi_{\alpha}, m$ are enrichment functions.

\subsection{Extended finite element method}

The finite element shape functions are also form a partition of unity:

$$
\sum_{i=1}^{n} N_{i}(x)=1 \text {. }
$$

It is convenient therefore to choose finite element shape functions that are partitions of unity. From equation (4), we note that the finite element space $\left(\psi_{1}=1, \psi_{\alpha}=0(\alpha \neq 1)\right)$ is a subspace of the enriched space $u^{h}$.

The enriched displacement approximation can be written as (see [2])

$$
u^{h}(x)=\sum_{I \in N} N_{I}(x)[u_{I}+\underbrace{H(x) a_{I}}_{I \in N_{\Gamma}}+\underbrace{\sum_{\alpha=1}^{4} F_{\alpha}(x) b_{I}^{\alpha}}_{I \in N_{\Lambda}}],
$$

where $u_{I}$ is the nodal displacement vector associated with the continuous part of the finite element, $a_{I}$ is the nodal enriched degree of freedom vector associated with the Heaviside (discontinuous) function, and $b_{I}^{\alpha}$ is nodal enriched degree vector associated with the elastic 
asymptotic crack tip function. In (5), $N$ is the set of all nodes in the mesh; $N_{\Gamma}$ is the set of nodes whose shape function support is cut by the crack interior (set of circles nodes); and $N_{\Lambda}$ is the set of nodes whose shape function support is cut by the crack tip $\left(N_{\Gamma} \cap N_{\Lambda}\right.$ $=\emptyset)($ sce Fig. 2).

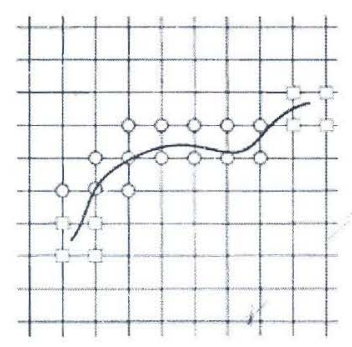

Fig. 2. Selection of enriched nodes for 2D crack problem

The interior of crack is modeled by the generalized Heaviside enrichment function $H$, where $H$ takes on the value +1 above the crack and -1 below the crack (see [2])

$$
H(x, y)=\left\{\begin{array}{l}
1 \text { if } y>0 \\
-1 \text { if } y<0
\end{array} .\right.
$$

The functions $F_{\alpha}$ are defined as:

$$
\left\{F_{\alpha}(r, \theta)\right\}=\left\{\sqrt{r} \sin \left(\frac{\theta}{2}\right), \sqrt{r} \cos \left(\frac{\theta}{2}\right), \sqrt{r} \sin \left(\frac{\theta}{2}\right) \cos \theta, \sqrt{r} \cos \left(\frac{\theta}{2}\right) \cos \theta\right\},
$$

where $(r, \theta)$ are the local polar coordinate at the crack tio. Note that the first function in $(7), \sqrt{r} \sin (\theta / 2)$, is discontinuous across the crack faces whereas the remaining three functions are continuous.

\section{ESTABLISH THE ELEMENT STIFFNESS MATRIX K $\mathbf{k}_{e}$}

\subsection{The element stiffness matrix}

Replace the expression of displacement approximation (5) in the weak form (2), the follow discrete system of linear equation is obtained:

$$
K . U=f
$$

where $K$ is the global stiffness matrix, $U$ is the vector of nodal unknowns and $f$ is external force vector. The element contribution to $K$ and $f$ are as follows:

$$
\begin{gathered}
k_{i j}^{e}=\left[\begin{array}{lll}
k_{i j}^{u u} & k_{i j}^{u a} & k_{i j}^{u b} \\
k_{i j}^{a u} & k_{i j}^{a a} & k_{i j}^{a b} \\
k_{i j}^{b u} & k_{i j}^{b a} & k_{i j}^{b b}
\end{array}\right], \\
f_{i}^{e}=\left\{\begin{array}{lllll}
f_{i}^{u} & f_{i}^{a} & f_{i}^{b 1} & f_{i}^{b 2} & f_{i}^{b 3}
\end{array} f_{i}^{b 4}\right\}^{T},
\end{gathered}
$$

where the submatrices and vectors in (8) are given by:

$$
k_{i j}^{m n}=\int_{\Omega_{e}}\left(B_{i}^{m}\right)^{T} D B_{j}^{n} d \Omega(m, n=u, a, b),
$$




$$
\begin{gathered}
f_{i}^{u}=\int_{\Gamma_{t} \cap \partial \Omega_{e}} N_{i} \bar{t} d \Gamma+\int_{\Omega_{e}} N_{i} b d \Omega, \\
f_{i}^{a}=\int_{\Gamma_{t} \cap \partial \Omega_{e}} N_{i} H \bar{t} d \Gamma+\int_{\Omega_{e}} N_{i} H b d \Omega, \\
f_{i}^{b \alpha}=\int_{\Gamma_{t} \cap \partial \Omega_{e}} N_{i} F_{\alpha} \bar{t} d \Gamma+\int_{\Omega_{e}} N_{i} F_{\alpha} b d \Omega .
\end{gathered}
$$

In equation (10), $\mathrm{B}_{i}^{u}, \mathrm{~B}_{i}^{a}, \mathrm{~B}_{i}^{b}$ are the matrices of shape function derivatives which are given by

$$
\begin{aligned}
& B_{i}^{u}=\left[\begin{array}{ll}
N_{i, x} & 0 \\
0 & N_{i, y} \\
N_{i, y} & N_{i, x}
\end{array}\right] \\
& B_{i}^{a}=\left[\begin{array}{ll}
\left(N_{i} H\right)_{, x} & 0 \\
0 & \left(N_{i} H\right)_{, y} \\
\left(N_{i} H\right)_{, y} & \left(N_{i} H\right)_{, x}
\end{array}\right], \\
& B_{i}^{b}=\left[\begin{array}{llll}
B_{i}^{b 1} & B_{i}^{b 2} & B_{i}^{b 3} & B_{i}^{b 4}
\end{array}\right]=\left[B_{i}^{b \alpha}\right](\alpha=1,4), \\
& B_{i}^{b \alpha}=\left[\begin{array}{ll}
\left(N_{i} F_{\alpha}\right)_{, x} & 0 \\
0 & \left(N_{i} F_{\alpha}\right)_{, y} \\
\left(N_{i} F_{\alpha}\right)_{, y} & \left(N_{i} F_{\alpha}\right)_{, x}
\end{array}\right] \quad(\alpha=1,4),
\end{aligned}
$$

we write $\left[B_{e}\right]=\left[\begin{array}{ccc}B_{i}^{u} & B_{i}^{a} & B_{i}^{b}\end{array}\right]$ in which case the element matrix becomes:

$$
K_{e}=\int_{\Omega_{e}} B_{e}^{T} D B_{e} d \Omega .
$$

Note that the functions $H$ and $F$ which describe crack face discontinuity appear in the finite element formulation. Numerical integration is used to calculate $K_{\epsilon}$.

\subsection{Numerical integration of the stiffness matrix}

The question arises of how best to perform the numerical integration. Elements not crossed by a discontinuity are readily integrated using standard three point Gauss quadrature. When elements contain a crack, we must modify the element quadrature routines to assemble accurately the contribution of the weak form equation on each side of the discontinuity. As the position of a crack in an element is arbitrary, standard Gauss quadrature may not be able to properly integrate the discontinuous field. In a cracked element, the domains $\Omega_{e}^{+}$and $\Omega_{e}^{-}$on other side of the discontinuity are triangulated into subdomains and three point Gauss quadrature used in each subdomain:

$$
\Omega_{e}=\sum_{\Delta} \Omega_{\Delta} .
$$

Note that the subdomains facilitate the integration without adding additional degrees of freedom. Since the modified integration scheme is needed only when an element contains a discontinuity, the additional computation burden is small.

Io implement the approach, Cast3M source code needs only one additional subroutine to deal with cracked elements. The combination of XFEM and subdomain technique avoids all potential meshing difficulties. Then simply solve $K U=f$ to obtain stresses and use these to determine the stress intensity factors. 

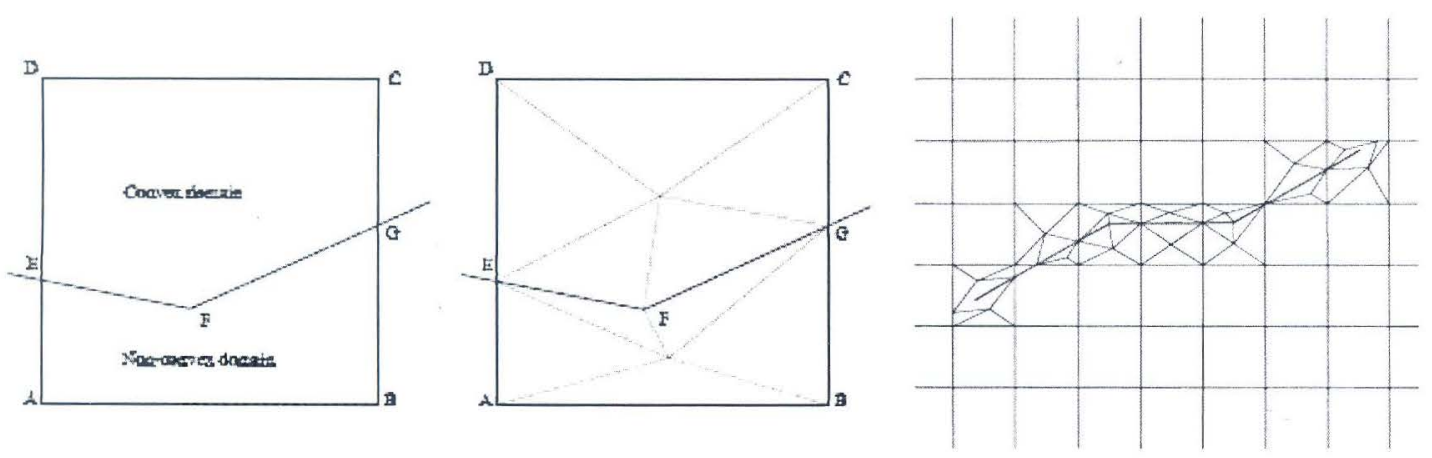

Fig. 3. Sub-triangles used in numerical integration

Numerical integration technique in above part let calculate the finite element with the crack using this new element for analyzing crack problem. We can receive the displacement and stress field for calculate stress intensity factor.

\section{CALCULATION OF STRESS INTENSITY FACTOR BY INTERACTION INTEGRALS}

This section describes the interaction integral technique due to Yau, Wang, \& Corten, 1980 [6]. Stress intensity factor solutions are obtained along a selected contour in terms of the known auxiliary solutions and field variables. The mixed-mode stress intensity factor solutions at the crack tip can be determined with ease and accuracy from information extracted in the far field.

The coordinates are taken to be the local crack tip coordinates with the $x_{1}$ axis parallel to the crack face. We consider two states of cracked body. State $1,\left(\sigma_{i j}^{(1)}, \varepsilon_{i j}^{(1)}, u_{i}^{(1)}\right)$, corresponds to the present state and state $2,\left(\sigma_{i j}^{(2)}, \varepsilon_{i j}^{(2)}, u_{i}^{(2)}\right)$, is an auxiliary state which will be chosen as the asymptotic fields for mode I or II. The $J$-integral for the sum of the two states is:

$$
\begin{aligned}
J^{(1+2)}=\int_{\Gamma} & {[\underbrace{\frac{1}{2}\left(\sigma_{i j}^{(1)}+\sigma_{i j}^{(2)}\right)\left(\varepsilon_{i j}^{(1)}+\varepsilon_{i j}^{(2)}\right)}_{W^{(1+2)}} \delta_{1 j}-\left(\sigma_{i j}^{(1)}+\sigma_{i j}^{(2)}\right) \frac{\partial\left(u_{i}^{(1)}+u_{i}^{(2)}\right)}{\partial x_{1}}] n_{j} d \Gamma } \\
J^{(1+2)}= & \int_{\Gamma}\left(W^{(1)} \delta_{1 j}-\sigma_{i j}^{(1)} \frac{\partial u_{i}^{(1)}}{\partial x_{1}}\right) n_{j} d \Gamma+\int_{\Gamma}\left(W^{(2)} \delta_{1 j}-\sigma_{i j}^{(2)} \frac{\partial u_{i}^{(2)}}{\partial x_{1}}\right) n_{j} d \Gamma \\
& +\int_{\Gamma}\left(W^{(1,2)} \delta_{1 j}-\sigma_{i j}^{(1)} \frac{\partial u_{i}^{(2)}}{\partial x_{1}}-\sigma_{i j}^{(2)} \frac{\partial u_{i}^{(1)}}{\partial x_{1}}\right) n_{j} d \Gamma \\
J^{(1+2)}= & J^{(1)}+J^{(2)}+I^{(1,2)} \\
I^{(1,2)}= & \int_{\Gamma}\left(W^{(1,2)} \delta_{1 j}-\sigma_{i j}^{(1)} \frac{\partial u_{i}^{(2)}}{\partial x_{1}}-\sigma_{i j}^{(2)} \frac{\partial u_{i}^{(1)}}{\partial x_{1}}\right) n_{j} d \Gamma
\end{aligned}
$$


where $W^{(1,2)}$ is the interaction strain energy

$$
W^{(1,2)}=\sigma_{i j}^{(1)} \varepsilon_{i j}^{(2)}=\sigma_{i j}^{(2)} \varepsilon_{i j}^{(1)} .
$$

For general mixed mode problems I and II, $J$-integral can be received from stress intensity factor $K_{I}$ and $K_{I I}$ using [5]:

$$
J=\frac{K_{I}^{2}+K_{I I}^{2}}{E^{\prime}},
$$

where $E^{\prime}=E$ for the plane stress, $E^{\prime}=E /\left(1-\nu^{2}\right)$ for the plane strain. Applying (16) to combined states gives:

$$
J^{(1+2)}=J^{(1)}+J^{(2)}+\frac{2}{E^{\prime}}\left(K_{I}^{(1)} K_{I}^{(2)}+K_{I I}^{(1)} K_{I I}^{(2)}\right) .
$$

Equation (21) and (24) lead to the following relationship:

$$
I^{(1,2)}=\frac{2}{E^{\prime}}\left(K_{I}^{(1)} K_{I}^{(2)}+K_{I I}^{(1)} K_{I I}^{(2)}\right) .
$$

Making the judicious choice of state 2 as the pure Mode I asymptotic fields with $K_{I}^{(2)}=1$ gives

$$
K_{I}^{(1)}=\frac{E^{\prime}}{2} I^{(1, \text { mode I })} .
$$

Mode II stress intensity factor can be determined in a similar way.

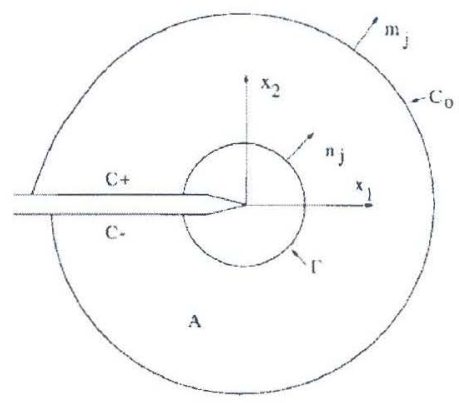

Fig. 4. Domain $\mathrm{A}$ is enclosed by $\Gamma, \mathrm{C}_{+}, \mathrm{C}_{-}, \mathrm{C}_{0}$. Unit normal $\mathrm{m}_{j}=\mathrm{n}_{j}$ on $\mathrm{C}_{0}, \mathrm{C}_{+}$, $\mathrm{C}_{-}$and $\mathrm{m}_{j}=-\mathrm{n}_{j}$ on $\Gamma$

The form of the contour integral (18) is not well suited to calculation. We therefore recast this integral into an equivalent domain form by multiplying the integrand by a sufficiently smooth weighting function $q(x)$ equal to unity on an open set containing the crack tip and equal to zero along an outer prescribed contour $C_{0}$. Then for each contour $\Gamma$ as in Fig.4, assuming the crack faces are traction free and straight in the region $A$ bounded by the contour $C_{0}$, the interaction integral becomes

$$
I^{(1,2)}=-\int_{C}\left(W^{(1,2)} \delta_{1 j}-\sigma_{i j}^{(1)} \frac{\partial u_{i}^{(2)}}{\partial x_{1}}-\sigma_{i j}^{(2)} \frac{\partial u_{i}^{(1)}}{\partial x_{1}}\right) q m_{j} d \Gamma .
$$


where the contour $C=\Gamma+C_{+}+C_{-}+C_{0}$ and $m$ is the unit outward normal to the contour $C$. From the divergence theorem, the integral interaction can be simplified to read:

$$
I^{(1,2)}=\int_{A}\left(\sigma_{i j}^{(1)} \frac{\partial u_{i}^{(2)}}{\partial x_{1}}+\sigma_{i j}^{(2)} \frac{\partial u_{i}^{(1)}}{\partial x_{1}}-W^{(1,2)} \delta_{1 j}\right) \frac{\partial q}{\partial x_{j}} d A
$$

$m_{j}=-n_{j}$ on $\Gamma$ and $m_{j}=\mathrm{n}_{j}$ on $\mathrm{C}_{0}, \mathrm{C}_{+}$and $\mathrm{C}_{-}$.

\section{NUMERICAL SIMULATION BY XFEM}

The crack procedure is summarized below:

- Define the mesh and crack geometry

- Partition cracked elements into triangles, enrich the nodes and numerically integrate to establish the stiffness matrix $K$.

- Solve $K U=F$ for the displacements.

- Use the displacement and resultant deformation fields to evaluate the interaction integrals.

\subsection{Plate with an edge crack:}

Consider a plate of width $w$ and height $L$ with an edge crack of length $a=45 \mathrm{~mm}$. The tensile stress $\sigma=100 \mathrm{MPa}$. The exact solution of this problem is given

$$
K_{I}=C \sigma \sqrt{a \pi}
$$

where $C$ is a finite geometry correction factor given by:

$$
C=1.12-0.231\left(\frac{a}{w}\right)+10.55\left(\frac{a}{w}\right)^{2}-21.72\left(\frac{a}{w}\right)^{3}+30.39\left(\frac{a}{w}\right)^{4} .
$$

Numerical results are shown in Figs. 5 and 6 :

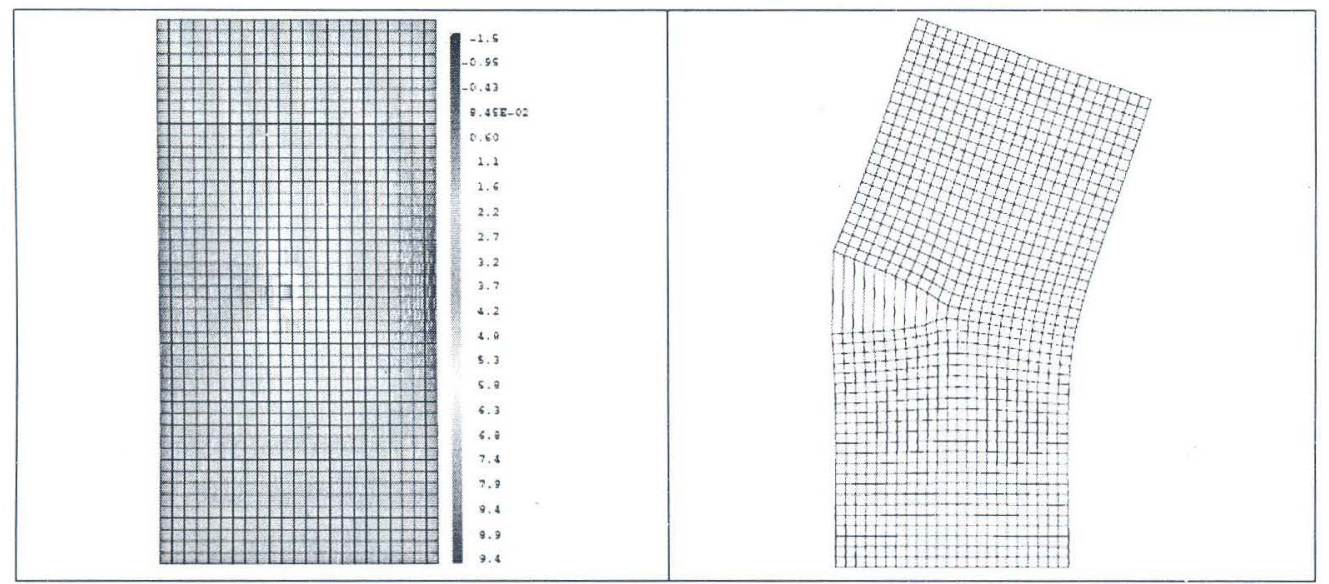

Fig. 5. Stress field yy with $w=100 \mathrm{~mm}, L=200 \mathrm{~mm}, a=45 \mathrm{~mm}$ Fig. 6. Deformation field

Remark: The method shows excellent agreement between numerical and theoretically exact solution with less than $1 \%$ variation in all cases (see Table 1 ). 
Table 1. The stress intensity factor $K_{I}$ subjected tensile stress $1 \mathrm{MPa}$

\begin{tabular}{cccc}
\hline & $\mathrm{K}_{\text {num }}$ & $\mathrm{K}_{\text {theory }}$ & Error (\%) \\
\hline $\mathrm{w}=100 \mathrm{~mm}, \mathrm{~L}=200 \mathrm{~mm}$ & 2.848 & 2.877 & -1.008 \\
$\mathrm{w}=110 \mathrm{~mm}, \mathrm{~L}=200 \mathrm{~mm}$ & 2.543 & 2.563 & -0.78 \\
$\mathrm{w}=120 \mathrm{~mm}, \mathrm{~L}=200 \mathrm{~mm}$ & 2.339 & 2.345 & -0.256 \\
$\mathrm{w}=130 \mathrm{~mm}, \mathrm{~L}=200 \mathrm{~mm}$ & 2.186 & 2.187 & -0.046 \\
$\mathrm{w}=140 \mathrm{~mm}, \mathrm{~L}=200 \mathrm{~mm}$ & 2.068 & 2.067 & -0.048 \\
$\mathrm{w}=150 \mathrm{~mm}, \mathrm{~L}=200 \mathrm{~mm}$ & 1.976 & 1.974 & 0.101 \\
\hline
\end{tabular}

\subsection{Plate with center crack}

Apply XFEM with FEM techniques to the following problem and compare results with the theoretically exact calculation.

Consider a cracked plate subjected to a tensile stress $\sigma=10 \mathrm{MPa}$, the width and length of this plate are $2 w$ and $2 h$. The crack is located at middle of plate and length=2a, $a=100$ mm.

Taking advantage of symmetry, we need only consider only one side of the plate. (see Fig. 7 and Fig. 8). Refer Ngo Huong Nhu et al., 2006 [5] for results obtained by CASTEM2000.

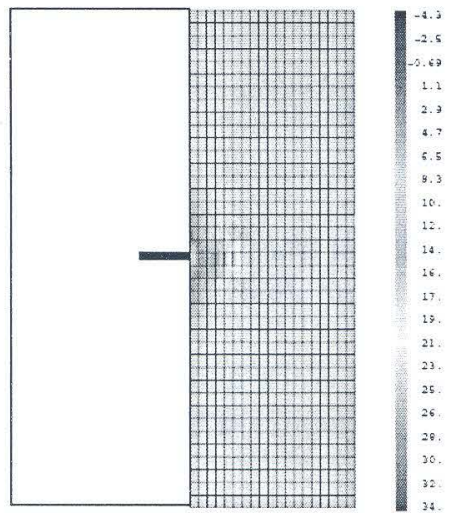

Fig. 7. Stress field yy with w $=400 \mathrm{~mm}$ Fig. 8. Deformation field

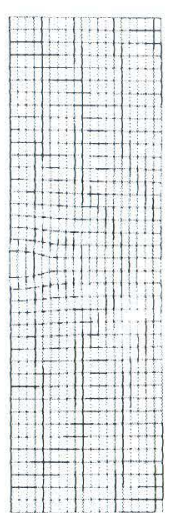

Table 2. Compare the results of XFEM with these ones of FEM [5] and theory

\begin{tabular}{cccc}
\hline $\mathrm{a} / \mathrm{w}$ & $\mathrm{K}_{I}(\mathrm{FEM})$ & $\mathrm{K}_{I}(\mathrm{XFEM})$ & $\mathrm{K}_{I}$ theory \\
\hline $1 / 2$ & 208.60 & 208.377 & 210.25 \\
$1 / 3$ & 188.73 & 188.949 & 190.07 \\
$1 / 4$ & 183.81 & 184.387 & 184.16 \\
\hline
\end{tabular}

Results indicate good agreement between XFEM using a simple mesh with those obtained using standard FEM (see Table 2). 


\section{CONCLUSION}

This paper extends the FEM by enriching FE approximations to solve crack related problems with minimal special purpose meshing. Partition of unity functions render the technique simple and robust and able to model discontinuous fields to at least the same degree of accuracy as do more complex standard FEM analyses. We commend the XFEM method as a useful tool to solve crack growth problems without re-meshing reducing computational effort without loss of accuracy. Future work will extend the method to handle multiple cracks.

\section{ACKNOWLEDGMENTS}

I wish express my sincere gratitude to Professor Ngo Huong Nhu and Professor Alain Millard, for their help to accomplish this paper.

This work is completed with the partly financial support from the Vietnam National Council of Natural Sciences.

\section{REFERENCES}

1. J. M. Melenk, I. Babuska, The partition of unity finite element method: Basis theory and application, Computer Methods in Applied Mechanics and Engineering 45 (5) (1999) 601620.

2. N. Moes, J. Dolbow, T. Belytschko, A finite element method for crack growth without remeshing, International Journal for Numerical Methods in Engineering 46 (1999) 131-150.

3. T. Belytschko, T. Black, Elastic crack growth in finite elements with minimal remeshing, International Journal for Numerical Methods in Engineering 45 (1999) 601-620.

4. N. Sukumar, J. H. Prevost, Modeling quasi-static crack growth with the extended finite element method, Part I: Computer implementation, International Journal of Solids and Structure 40 (2003) 7513-7537.

5. Ngo Huong Nhu, Nguyen Truong Giang, Calculation of fracture mechanic parametres via fem for some cracked plates under different loads, Vietnam Journal of Mechanics 28 (2) (2006) 82-93.

6. J. F. Yau, S. S. Wang, H. T. Corten, A mixed-mode crack analysis of isotropic solids using conservation law of elasticity, Journal of Applied Mechanics 47 (1980) 335-341.

Received January 25, 2008

\section{MÔ PHỎNG SỐ VẾT NƯT 2D BẰNG PHẦN TỬ KHÔNG LIÊN TỤC}

Xác định các hệ số tập trung ứng suất là rất quan trọng trong cơ học phá huỷ. Phương pháp phần tử hữu hạn mở rộng (XFEM) đã cho phép giải nghiệm chính xác và nhanh chóng hơn để xác định các hệ số này. Bài viết này miêu tả một vài kết quả khi phân tích bản nứt thông qua XFEM. Những kiểu phần tử mới cho phép thể hiện vết nứt độc lập trong lưới phần tử đã được xây dựng. Những phần tử này dựa trên hàm không liên tục và miền tiệm cận chuyển vị đỉnh vết nứt của cơ học phá huỷ. Mã nguồn Fortran trên phần mềm CAST3M đã được phát triển và áp dụng những phần tử này để tính toán một vài ví dụ. Miền ứng suất và biến dạng thu được sẽ được dùng tính hệ số tập trung ứng suất thông qua tích phân tương tác. Kết quả tính toán được so sánh với kêt quả FEM và lý thuyết để thấy được lợi thế của loại phần tử này. 